\title{
PEMBERDAYAAN USAHA KERAJINAN TEMBAGA MELALUI PENGEMBANGAN DESAIN DAN PELATIHAN PEMBUKUAN
}

\author{
Oleh: \\ Mulyanto dan Dewi Kusuma Wardani \\ Fakultas Keguruan dan Ilmu Pendidikan, \\ Universitas Sebelas Maret Surakarta
}

Email: mulyantosr@yahoo.com,mulyanto@staff.uns.ac.id

\begin{abstract}
ABSTRAK
Tujuan kegiatan pengabdian ini adalah pemberdayaan usaha kecil kerajinan tembaga melalui pengembangan desain produk dan pembenahan pembukuan. Kegiatan ini dilaksanakan di usaha Mashuri dan usaha Rofiq di Desa Tumang, Kecamatan Cempogo, Kabupaten Boyolali, Propinsi Jawa Tengah melalui pendekatan tindakan partisipatif, pendidikan orang dewasa, pengembangan kreatifitas, diskusi terfokus, dan belajar mandiri. Langkah-langkah tindakan disesuaikan dengan teori pengembangan desain yaitu diawali dengan melakukan analisis kebutuhan pasar, penyusunan konsep dan perencanaan produksi, proses kreatif, uji produk, proses produksi, dan diakhiri dengan evaluasi. Hasil kegiatan ini yaitu para pengrajin tembaga mitra telah mampu memproduksi berbagai produk dengan menggunakan bahan baku plat tembaga dan kuningan baik produk yang berbentuk tunggal maupun produk dalam bentuk komponen, dan mampu memproduksi produk dengan teknik tempa, teknik ukir, teknik plat, dan teknik anyaman. Selain itu, pengrajin juga mampu membuat pembukuan sehingga mengetahui kinerja usahanya. Luaran kegiatan berupa produk-produk baru yang sebelumnya belum pernah dikerjakan yang terdiri atas tiga aspek, yaitu (1) katalog berupa berbagai tekstur produk dan berbagai jenis finishingnya sebagai sampel untuk media promosi secara nyata, (2) produk-produk kerajinan tembaga secara utuh, dan (3) produk kerajinan tembaga yang berupa komponen. Produk tembaga yang bersifat utuh meliputi berbagai lampu gantung dan lampu taman dengan berbagai teknik finishingnya. Produk tembaga yang bersifat komponen yaitu berupa komponen atap kubah masjid yang berbentuk belah ketupat berukir dengan berbagai ukuran dan kaligrafi komponen pintu masjid.
\end{abstract}

Kata kunci: pengembangan, desain produk, kerajinan, tembaga, pembukuan 


\section{ABSTRACT}

The aim of this public service is to empower small businesses of copper craft through product design development and repairing bookkeeping. This activity was carried out in Mashuri's and Rofiq's businesses in Tumang Village, Cempogo Subdistrict, Boyolali Regency, Province of Central Java through a participatory action approach, an adult education, the development of creativity, focused discussions, and independently learning. The steps of these actions were adapted to a theory of design development, that is, start with analysing market needs, drafting concept and planning production, creative process, test product, production process, ends with an evaluation. The result of this activity is the copper craftsmen partners have been able to produce various products using raw material of copper and brass plate, either product in a single shaped or product in the form of component; and have been able to make products using forging, carving, plate, and plaiting techniques. Besides that, the craftsmen are also capable to make bookkeeping, so that they know their business performance. The outcome of the activity is new products that not made before, that is, (1) catalog about the various textures of the product and all sorts of finishing processes as a sample for promotion media in real, (2) intact products of copper craft, and (3) product of copper craft in the form of component. The intact copper products are chandelier and garden lights with various techniques of finishing. The copper product in the form of component is a component of carved mosque roof dome in rhombic shape with various size; and calligraphy of the component of door of the mosque.

Keywords : development, product design, craft, copper, bookkeeping

\section{PENDAHULUAN}

Kondisi wilayah Kabupaten Boyolali Propinsi Jawa Tengah sebagian besar merupakan tanah kering seluas 78.308 hektar $(70 \%)$, tanah sawah seluas 23.201 hektar $(23 \%)$, dan tanah pekarangan $(7 \%)$. Berdasarkan Dinas Perindustrian Perdagangan Propinsi Jawa Tengah, Boyolali memiliki beberapa produk unggulan, komoditas yang dapat dikembangkan sebagai peningkatan pendapatan ekonomi daerah maupun bagi pengrajin. Produk kerajinan tembaga merupakan komoditas potensial, dan komoditas andalan.
Produk kerajinan tembaga memberikan kontribusi besar bagi pendapatan daerah. Produk ini selain memiliki pasar di dalam negeri juga telah memiliki pasar ekspor ke berbagai negara seperti Canada, Jepang, Belanda, Amerika, Australia, dan beberapa negara di Eropa. Hanya saja frekuensi pemasaran produk eksport ini tidak ajeg atau bersifat fluktuasi. Bahan dasar kerajinan tembaga adalah tembaga, sedangkan bahan lainnya berupa kuningan, besi, aluminium, dan kayu. Bahan-bahan tersebut diperoleh dari wilayah Solo atau import. Usaha kerajinan tembaga di Kabupaten Boyolali berpusat di wilayah Kecamatan 
Cempogo yaitu tersebar di Desa Tumang, Desa Cabean Kunthi dan Desa Kembang Kuning. Pada tahun 2011, jumlah usaha skala kecil menengah (UKM) kerajinan tembaga di Kabupaten Boyolali mencapai 400 unit, dengan tenaga kerja mencapai 1.070 orang (Tabel $1)$.

Table 1 Kondisi UKM Tembaga Boyolali Th 2011

\begin{tabular}{llrrrr}
\hline \multirow{2}{*}{ No } & \multirow{2}{*}{ Uraian } & \multicolumn{3}{c}{ Kec. Cempaga } & \multirow{2}{*}{ Total } \\
\cline { 3 - 5 } & & Tumang & $\begin{array}{c}\text { Ds.Kemban } \\
\text { g Kuning }\end{array}$ & $\begin{array}{c}\text { Desa } \\
\text { Cabean }\end{array}$ & \\
\hline 1 & Jumlah UKM & 266 & 116 & 18 & 400 \\
2 & Tenaga kerja & 795 & 230 & 45 & 1.070 \\
3 & Investasi US \$ & 162.500 & 210.150 & 31.400 & 404.050 \\
4 & Volume produk & 25.080 & 13.920 & 1.700 & 40.700 \\
& (item) & & & & \\
5 & Volume (ton) & 7.018 & 18.500 & 5 & 30.518 \\
6 & Nilai US \$ & 3.762 .000 & 584.640 & 71.400 & 4.418 .040 \\
\hline
\end{tabular}

Produk kerajinan tembaga dari Kabupaten Boyolali dapat dikategorikan menjadi tiga kelompok. Kelompok pertama, berupa barang kerajinan untuk pemenuhan kebutuhan rumah tangga seperti dandang, panci, wajan, kenceng, klenting, dan aneka alat dapur lainnya. Kelompok kedua, berupa barang kerajinan seni yaitu seperti jambangan, aneka vas bunga, lampu, pigura foto, tempat tisu, hiasan dinding, lukisan, risplang, kubah masjid/gereja, plafon, dan aksesoris lainnya. Kelompok ketiga, berupa kerajinan mebel seperti meja, kursi, almari, pintu, jendela, dan sebagainya.

Teknologi proses produksi yang biasanya diterapkan untuk memproduksi kerajinan tembaga dapat dibagi menjadi tiga, yaitu proses dengan teknik tempa, teknik plat, dan teknik ukir. Langkahlangkah proses produksi kerajinan tembaga adalah sebagai berikut: Proses produksi kerajinan tembaga yang dibuat dengan teknik tempa, biasanya untuk membuat barangbarang yang volumenya kecil dan bentuknya cembung sederhana seperti dandang dan kenceng. Alur proses produksi produk yang menggunakan teknik tempa yaitu (1) pembuatan desain produk di atas kertas menggunakan pensil atau pen; (2) pembuatan pola pada kertas atau papan triplek tergantung kebutuhan dengan cara digunting atau digergaji; (3) pengolahan atau peleburan tembaga dengan alat blower; (4) penempaan dan pembentukan plat tembaga menjadi barang sesuai desain; dan (5) proses finishing.

Proses produksi kerajinan tembaga yang dilakukan dengan teknik plat biasanya digunakan untuk membuat barang-barang yang volumenya besar atau memiliki permukaan luas, seperti 
bathub. Alur proses produksi dengan teknik plat adalah sebagai berikut (1) pembuatan desain produk di atas kertas menggunakan pensil; (2) pembuatan pola atau mal pada kertas atau papan triplek sesuai kebutuhan dengan cara digunting atau digergaji; (3) pemotongan lembaran plat tembaga; (4) pembentukan dan atau penyambungan atau perangkaian plat tembaga menjadi bentuk produk sesuai desain dengan cara plat disambung dengan teknik dilas; (5) pengepresan plat agar permukaan menjadi rata; dan (6) proses finishing.

Proses produksi kerajinan tembaga dengan teknik ukir biasanya diterapkan untuk membuat berbagai barang yang memiliki permukaan datar seperti relief, selain itu ada pula teknik ukir diterapkan pada permukaan barang yang memiliki volume seperti dandang. Barang yang mempunyai volume juga sering diberi sentuhan ukir sebagai komponen penghias. Alur proses produksi kerajinan tembaga dengan teknik ukir adalah sebagai berikut: (1) pembuatan desain produk di atas kertas menggunakan pensil atau pen; (2) pembuatan pola atau mal pada kertas atau papan triplek sesuai kebutuhan dengan cara digunting atau digergaji; (3) pemotongan lembaran plat tembaga sesuai dengan ukuran pola; (4) pembuatan adonan jabong yang terdiri atas bubuk batu bata dan oli bekas; (5) pengisian jabong ke dalam model atau peletakan jabong di bawah permukaan plat tembaga yang akan diukir guna sebagai landasan pengukiran agar prosesnya terasa elastik; (6) pe-ngukiran permukaan tembaga dengan matras atau cetak; (7) pengukiran permukaan tembaga dengan tatah secara manual untuk menyem-purnakan hasil ukiran dengan matras; (8) pelepasan jabong dari model dengan menggunakan blower atau pelepasan plat dari matras; dan (9) proses finishing.

Produk kerajinan tembaga setelah menjadi bentuk yang diinginkan sesuai desain melalui beberapa teknik tersebut di atas, kemudian dilakukan proses finishing. Tahapan finishing kerajinan tembaga sebagai berikut (1) penghalusan sambungan plat yang diakibatkan oleh proses patri atau las dengan alat gerinda; (2) pembentukan motif tekstur pada permukaan produk atau pengukiran permukaan produk dengan alat tatah; (3) pembersihan model dengan zat asam solfat $\left(\mathrm{H}_{2} \mathrm{SO}_{4}\right)$ dan $\mathrm{HNO}_{3}$; (4) pewarnaan permukaan produk dengan cara diolesi zat kimia (Sn) akan dihasilkan warna hitam, pemberian nitrit pada permukaan produk akan dihasilkan tekstur seperti jamur berwarna coklat kehijauhijauan kusam (antic); dan (5) pemolisan permukaan yang polos dengan bahan langsul dan siken dengan mesin polis dihasilkan warna gilap.

Target luaran kegiatan di usaha kerajinan tembaga ini adalah aspek produksi berupa desain 
produk kerajinan tembaga yang baru sekaligus produk-produknya, dan aspek pembukuan lebih tertata dan katalog terbarui. Target luaran kegiatan ini dilihat dari teknik produksinya ada tiga, yaitu produk yang diproduksi menggunakan teknik tempa minimal 3 produk yang berbeda, produk yang diproduksi dengan teknik ukir minimal 1 produk, dan produk yang diproduksi dengan teknik plat minimal 1 produk. Selain itu juga ditargetkan dihasilkan sampel berbagai tekstur produk sebagai media promosi secara nyata, dan pengrajin tembaga mampu menyusun laporan keuangan yang meliputi aliran kas, neraca dan laporan rugi/laba.

\section{METODE}

Target luaran di atas dicapai melalui tahapan kegiatan sebagai berikut. Tim bersama mitra mendiskusikan berbagai desain produk yang dibuat. Desain produk yang dikerjakan dipilih desain-desain yang diproyeksikan dapat diterima oleh pasar (Wong, 1986), namun desain tersebut belum pernah dibuat oleh mitra. Desain-desain produk ditetapkan terdiri atas desain produk berbagai lampu, desain ukir untuk diterapkan pada bangunan, desain untuk diterapkan pada produk yang memiliki volume besar yaitu bathud, dan pembuatan sampel berbagai jenis motif tekstur produk. Selain itu juga direncanakan dilakukan penyem-purnaan catalog produk.
Metode pendekatan yang diterapkan dalam kegiatan ini meliputi pendekatan partisipatif, pendekatan individual, metode diskusi kelompok terfokus (Grenbauw, 1988), dan analisis pasar. Metode diskusi terfokus dan analisis pasar dilakukan untuk menganalisis dan menentukan desain produk yang dibuat dan motif tekstur yang menjadi tren pasar pada saat ini, dan sekaligus desain tersebut mampu dikerjakan oleh para karyawan mitra. Pendekatan partisipatif, yaitu usaha mitra yang terdiri pengusaha dan tenaga kerjanya dilibatkan ikut berpartisipasi secara aktif dalam semua kegiatan sesuai bidangnya masing-masing, sehingga mereka benar-benar mampu mandiri memahami kebutuhan riilnya dan mampu memecahkan masalahnya sendiri meskipun kegiatan ini telah berakhir. Pendekatan individual dilakukan untuk mendampingi setiap pengrajin dalam melakukan proses produksi setiap desain produk dan membuat laporan keuangan.

Pelaksanaa kegiatan pokok secara berurutan dalam setiap kelompok produk adalah sebagai berikut. Pengembangan desain produk dilakukan melalui tahapan sebagai berikut: (1) analisis produkproduk yang diminati oleh pasar dan mampu dikerjakan (Frinces, 2011; Wong, 1986), (2) penyusunan konsep desain, perencanaan produksi, pembuatan gambar desain produk, pembuatan pola, pembuatan matras, penempaan atau pengukiran produk, dan 
melakukan finishing produk berpartisipasi secara aktif agar (Clipson dalam Rizali, 2006). setelah kegiatan ini berakhir usaha Pembuatan sampel motif-motif mitra tetap mampu mengatasi tekstur dilakukan melalui tahapan masalahnya terutama dalam sebagai berikut: (1) melakukan analisis semua motif tekstur yang telah ada dan telah dibuat, (2) penyusunan konsep motif tekstur, analisis dan penentuan variasi ketebalan bahan, analisis dan penentuan jenis finishing, dan penentuan ukuran bidang sampel, (3) pembuatan gambar desain motif tekstur, (4) pembuatan motif tekstur pada plat tembaga, di antara plat tersebut dibuat dengan berbagai ukuran dan diantara plat tersebut dibuat berbagai jenis finishing. Kegiatan memperbarui katalog dilakukan melalui tahapan sebagai berikut pengembangan desain secara berkelanjutan secara mandiri.

Partisipasi usaha mitra antara lain dalam beberapa kegiatan seperti: (1) melakukan identifikasi berbagai kebutuhan nyata yang berkaitan dengan pengembangan usahanya, (2) mengidentifikasi dan menentukan desain-desain produk dan motif tekstur yang diminati oleh konsumen, (3) memilih dan menentukan desain-desain produk baru yang diproduksi, melakukan pendokumentasian produk-produk kerajinan tembaga, (5) pembenahan manajemen mendokumentasikan produkproduk yang belum terdokumentasi, (2) mengedit pemasaran melalui penyempurnaan katalog dan spesifikasi produk, dan gambar-gambar produk, (3) mengidentifikasi dokumen mengedit spesifikasi bahan dan kegiatan transaksi yang dilakukan produk, dan (4) mengedit harga. untuk data laporan keuangan. Selama kegiatan berlangsung, Berikut tahapan pelaksanaan usaha mitra dilibatkan kegiatan dalam gambar.

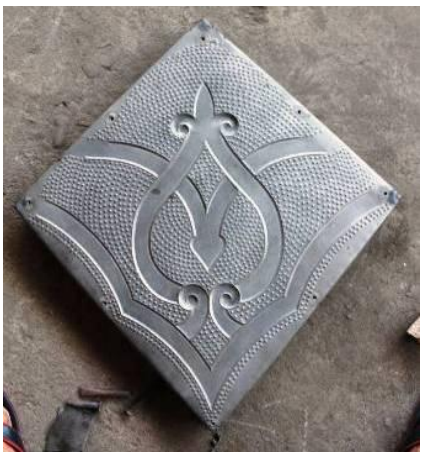

Gambar 1.

Pembuatan matras

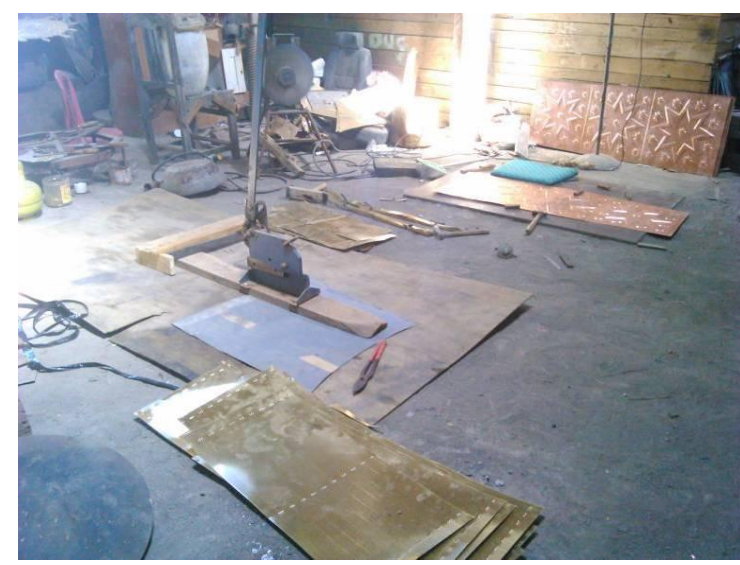

Gambar 2.

Pemotongan plat tembaga sesuai ukuran 


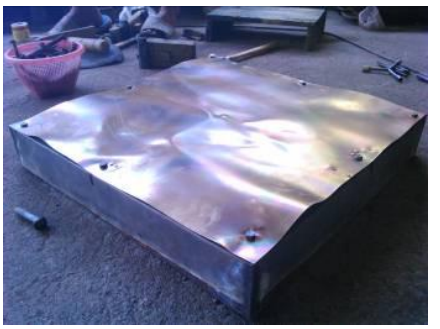

Gambar 3.

Pemasangan plat tembaga pada matras, plat dikunci di 8 titik

\section{HASIL DAN PEMBAHASAN}

Hasil yang dicapai kegiatan ini ada dua kategori, yaitu aspek produksi dan aspek manajemen usaha, yaitu (1) desain produk berbagai lampu gantung sebanyak 8 buah yang dibuat dengan teknik tempa dan teknik anyaman. (2) Desain motif atap kubah masjid, yang terdiri atas produk matras untuk membuat potonganpotongan atap bermotif, dan produk yang berupa atap kubah bermotif yang dikerjakan dengan teknik ukir dengan matras dan manual. Desain produk kaligrafi huruf arab yang diterapkan sebagai ornament pintu masjid. (3) Desain produk bak mandi (bathub) sebanyak 1 buah yang dibuat dengan teknik plat. (4) Tekstur permukaan produk tembaga berbagai motif yang digunakan sebagai sampel produk ketika pengrajin melakukan transaksi penjualan. (5) Katalog produk yang memuat keterangan mengenai gambar produk, ukuran produk, spesifiksi bahan, jenis finishing, dan harga. (6) Dokumen laporan keuangan untuk mengetahui posisi kinerja usaha yang digunakan sebagai dasar pengambilan keputusan di bidang manajemen, produksi maupun pasar.

Secara rinci hasil kegiatan dapat dijelaskan sebagai berikut.

1. Desain produk lampu

Berdasarkan pengalaman pengajin selama 5 tahun terakhir dan analisis pengrajin terhadap penjualan produk para usaha kerajinan tembaga lainnya, dapat disimpulkan bahwa produk-produk kerajinan tembaga yang paling laris saat ini adalah lampu gantung, aksesoris masjid, dan aksesoris hotel. Dengan demikian desain produk yang di-kembangkan dalam kegiatan ini yaitu berbagai desain lampu gantung dan aksesoris masjid. Lampu gantung yang dibuat antara lain lampu berbentuk sangkar ayam bali, keranjang, 
bola, buah delima, buah salak, kendi, caping, dan terompet. Produk-produk yang dibuat telah mempertimbangkan beberapa aspek seperti aspek estetika, fungsional, ergonomis, teknik, ekonomis, sosial budaya, dan lingkungan (Prasetyowibowo, 1998). Produk lampu tersebut dibuat dengan teknik anyaman dan tempa. Selain itu teknik finishingnya juga dilakukan dengan berbagai teknik seperti teknik polis, teknik diolesi Sn, dan diolesi asam nitrit. Khusus produk lampu yang dibuat dengan teknik anyaman dalam hal ini yang berbentuk sangkar ayam dan keranjang, agar bola lampu tidak kelihatan secara langsung dari luar dan untuk lebih memperindah penampilan, maka pada bagian dalam keranjang ditambahkan fiber glass putih yang berbentuk menyerupai bentuk lampu. Penerapan lampu sangkar dan lampu keranjang di atas dapat digantung dan juga dapat dipasang di bawah sebagai lampu taman.

2. Desain atap kubah masjid

Desain atap kubah masjid dibuat berbentuk segiempat belah ketupat. Potongan atap paling bawah berukuran diagonal sekitar $55 \mathrm{~cm} \times 60 \mathrm{~cm}$, semakin ke atas ukuran diagonal belah ketupat makin mengecil. Agar pekerjaan dapat mencapai efektif dan efisien, maka secara teknis proses pengukiran dilakukan dengan cara menggunakan matras sesuai dengan ukuran masingmasing. Matras dibuat dari bahan plat besi yang di bagian landasannya terbuat dari adonan jabong (bubuk batu bata dan oli). Cara mengukir plat, plat tembaga dipotong-potong sesuai ukuran kemudian satu persatu diletakkan di atas matras dan dikunci di 8 titik agar plat tidak bergeser ketika dilakukan proses tempa. Kemudian plat ditempa menggunakan palu kayu yang kepalanya dilapisi karet, tujuannya agar proses pemukulan dapat elastis. Setelah plat tembaga tersebut membentuk motif sesuai motif pada matras kemudian plat dilepas dan bentuk motif disempurnakan dengan tatah secara manual sesuai dengan bentuk yang diinginkan.

3. Desain bak mandi

Desain produk bak mandi (bathub) dibuat sesuai ukuran orang Indonesia yaitu panjang $160 \mathrm{~cm} \times$ lebar $60 \mathrm{~cm} \times$ tinggi $55 \mathrm{~cm}$. Desain bak mandi tersebut dibuat ergonomi dan sangat sederhana atau minimalis, agar bak tersebut dapat diletakkan di dalam kamar mandi yang berukuran tidak terlalu longgar.

4. Sampel tekstur permukaan produk

Sampel tekstur permukaan produk dibuat berdasarkan berbagai jenis motif tekstur yang pernah dan dapat dibuat, berbagai ukuran plat tembaga, 
berbagai jenis teknik finishing. Tekstur permukaan dibuat pada plat berukuran $20 \mathrm{~cm} \times 20 \mathrm{~cm}$.

5. Katalog produk memuat gambar-gambar produk, ukuran volume produk, jenis bahan baku, jenis finishing, dan harga. Katalog produk digolongkan atas berbagai jenis produk seperti lampu, mangkok, gusi, anyaman, patung, relief, frame, meja, vas, wastafel dan bathub.

6. Laporan keuangan meliputi aliran kas harian, neraca dan laporan rugi/laba secara periodik (bulanan).

\section{KESIMPULAN}

Berdasarkan proses pelaksanaan dan hasil yang dicapai dalam kegiatan pemberdayaan usaha kerajinan tembaga skala kecil ini dapat disimpulkan sebagai berikut. Pengrajin tembaga mitra telah mampu membuat sebagian besar produk-produk kerajinan yang menggunakan bahan baku plat tembaga dan kuningan terutama yang penggarapannya hanya dapat dilakukan secara manual. Produk-produk yang dapat digarap yaitu produk yang dibuat dengan teknik tempa, teknik plat, teknik ukir, dan teknik anyaman. Beberapa teknik finishing yang dapat dikerjakan antara lain teknik polis glos ataupun semi glos, teknik oles dengan Sn, dan teknik oles dengan asam nitrit. Jika usaha mitra memperoleh pesanan garapan model-model yang berukir dalam jumlah besar, proses produksi dikerjakan menggunakan matras atau cetakan. Apabila model yang dikerjakan memiliki bidang sempit atau sekitar $15 \mathrm{~cm} \times 15 \mathrm{~cm}$ proses cetak digunakan teknik pres, sedangkan jika model yang digarap memiliki bidang yang luas seperti $50 \mathrm{~cm} \times 50 \mathrm{~cm}$ proses cetak dilakukan melalui teknik tempa. Kemudian hasil dari proses cetak ataupun tempa di atas disempurnakan dengan teknik ukir secara manual. Hal tersebut dilakukan agar proses produksi lebih efektif dan efisien. Produkproduk kerajinan tembaga yang memakan ruang yang besar, hal ini telah dirancang agar produk dapat dikemas dengan mudah. Pada bagian produk tertentu dibuat potongan-potongan dan potongan tadi dapat dirangkai lagi dengan mudah. Misalnya, produk lampu gantung yang berbentuk buah salak dan memiliki tangkai gantungan panjang, maka pada bagian lampu dan tangkai gantung dibuat dapat dilepas, sehingga memudahkan dalam proses pengemasan. Sampel tekstur permukaan produk berbagai jenis motif, berbagai sampel ukuran plat tembaga, dan berbagai jenis teknik finishing, sangat bermanfaat sebagai pendukung promosi produk secara langsung. Dengan melihat sampel ini konsumen lebih percaya, komunikasi konsumen dan mitra lebih cepat tercapai. Pengrajin tembaga diharapkan membuat catatan keuangan secara rutin untuk mempermudah akses permodalan dan mengetahui kinerja usaha. 
DAFTAR PUSTAKA

Frinces, Henflin Z. 2004.

Kewirausahaan dan Inovasi

Bisnis. Yogyakarta:

Darussalam.

Moelyono, $\quad$ Mauled. 2010. Menggerakkan Ekonomi

Kreatif: Antara Tuntutan dan Kebutuhan. Jakarta: Rajawali.

Prasetyowibowo, Bagas. 1998. Desain Produk Industri. Bandung: Yayasan Delapan Sepuluh

Rizali, Nanang. 2006. Tinjauan Desain Tekstil. Surakarta: LPP UNS.

Rohman., Zulaikha., Rahardjo., Harto. 2011. Kajian Terhadap Kapabilitas
Pembukuan Terhadap Usaha Kecil dan Menengah Dalam Mendukung Perilaku Kepatuhan Wajib Pajak. Jurnal Akuntansi volume XV (September 2011): p. 327-343. Semarang: Undip

Sawitri., Sicilia, Rina Rachmawati dan Rodia Syamwil. 2010. Pengembangan Kreativitas Pengrajin pada Industri Kreatif Kain Perca di Kabupaten Semarang. Jurnal Inovasi dan Perekayasa Pendidikan, 3.1 (Desember 2010): p401-422.

Wong, Wusius. 1986. Beberapa Asas Merancang Dwimatra. Terjemahan Adjat Sakri. Bandung: ITB. 